\title{
The new age of direct marketing
}

Received (in revised form): 6th February, 2003

\section{Shena Mitchell}

is a senior marketing lecturer at the University of Portsmouth Business School where she specialises in marketing research and consumer behaviour. Her research and business consultancy interests include direct marketing, database marketing, marketing research, business ethics, internal marketing and consumer privacy. She has a wide knowledge, strengthened by ten years' hands-on experience, of both quantitative and qualitative data collection methods.

\begin{abstract}
This study is the first of its kind to focus upon consumer attitudes towards unsolicited direct mail and telesales with the aim of creating discrete consumer segments based upon their attitudes, thus enabling organisations to target consumers in a more precise and effective way. The author believes that 'attitudinal communication segmentation' will play a significant role in the future in an organisation's planning of its marketing communication strategies. The literature on attitudinal research, consumer privacy and segmentation is briefly reviewed and the findings from exploratory focus groups and a self-administered attitudinal survey, conducted in the UK, are presented.
\end{abstract}

\section{INTRODUCTION}

Direct marketing has been one of the most significant developments in marketing in recent years. The UK has demonstrated one of the fastest direct marketing growth rates in Europe; the various statistical sources, the list industry and the wealth of the direct marketing agencies all point to a dynamic and fast-evolving industry. Direct mail and telemarketing are by far the most significant types of media used by direct marketers to achieve this growth.

Many marketers consider that this growth will continue due to a variety of factors, such as technological improvements in database creation and analysis, a degree of disenchantment with traditional media such as television (which is increasingly being questioned on the grounds of cost, value and ability to target accurately), the increase in accountability and measurability imposed on marketers, the advent of the cashless society, and the continuing fragmentation and proliferation of products and brands, based in part on a demand for greater individualism in the marketplace.

On the one hand, it could be argued that there is scope for further growth, as marketing databases become more sophisticated and accurate, as technology allows this information to be converted into more efficiently targeted marketing, and as consumer demand increases for an ever-more customised contact. On the other hand, however, it could be argued that consumers are already over-targeted in some industries. For some it has reached saturation point and the rate of return on capital employed is dropping. Consumer concerns about information privacy and physical privacy have led to further governmental intervention which has dictated an increase in legislation. The prospect of litigation is becoming very real for those organisations that do not manage consumer data appropriately. If this is the case then, in order to 
remain effective, direct marketing activities will need to become even more finely tuned, limiting the amount and type of promotions sent, and using more precise and accurate methods of analysis to target discrete consumer segments. The implication is that by identifying a substantial homogeneity in attitudes towards specific media types, along with more traditional information such as demographic and lifestyle data, direct marketers can improve personal contact through the identification of new and improved target markets.

The research reported here focuses on consumer attitudes towards unsolicited direct mail and telesales in the UK, with the aim of determining the value, if any, of attitudinal segmentation. The research concludes that the identification and application of attitudinal segmentation bases, in the context of unsolicited direct mail and telesales, could improve relationships between marketer and consumer, via improved consumer contact and information handling practices. Limited research has been conducted into the attitudes that consumers hold concerning unsolicited direct mail and telesales, ${ }^{1-3}$ despite the growing importance of consumer attitudes towards privacy. ${ }^{4,5}$

The aim of this research was to discover not only what attitudes are held by consumers, but what kind of consumers hold earnest attitudes either for, or against, unsolicited direct mail and telesales, and hence to segment the market for targeting purposes. The assumption was that consumers who do not like unsolicited direct mail or telesales are less likely to purchase the offering, regardless of the suitability of the other elements of the marketing mix. It was hoped to be able to identify discrete consumer segments based upon consumer attitudes towards unsolicited direct mail and telesales in the UK.

\section{METHODOLOGY}

Two approaches were used; the first was a series of focus groups, the second a self-administered attitudinal survey. These approaches were used to examine two key hypotheses:

$\mathrm{H}_{1}$ : The salience of a consumer's attitude towards behaviour, subjective norm and perceived control in relation to unsolicited direct mail and telesales will affect the consumer's behaviour. $\mathrm{H}_{2}$ : Consumers can be segmented into discrete identifiable groups, based upon their thresholds towards information privacy and physical privacy.

\section{Focus groups}

The overall aim of the focus groups was to gather qualitative data that would identify consumer attitudes towards unsolicited direct mail and telesales. The specific objectives were to:

- determine the sample population's cognitive, affective and conative attitude dimensions towards unsolicited direct mail and telesales

— identify participants' thresholds towards information privacy and physical privacy in relation to unsolicited direct mail and telesales.

This study aimed to identify the cognitive, affective and conative components of the attitude formation, whereas comparable research has tended to study belief only. The research aims were phenomenological in nature, based on a need to understand the everyday experience of the consumer. ${ }^{6}$ Therefore, phenomenological focus groups were used to determine the degree of inter-subjectivity regarding various topics, by examining the way in which group members relate to each other, and by providing insights about the extent to 
Table 1: Composition of focus groups

\begin{tabular}{lllc}
\hline Group & Gender & SOC & Number in focus group \\
\hline Group A & Female & C1 and below & 10 \\
Group B & Female & AB & 9 \\
Group C & Male & C1 and below & 12 \\
Group D & Male & AB & 8 \\
\hline Total number & & & 39 \\
\hline
\end{tabular}

which their experiences and their ways of describing their experiences are shared. ${ }^{7,8}$

Empirical research to date has concurred that consumers tend to be mainly concerned about the environment, the timeliness of the promotion, accuracy, relevance, physical and information privacy. The research consisted of four focus groups ${ }^{9,10}$ lasting for 90 minutes each and using a stratified convenience quota of homogeneous strangers ${ }^{11,12}$ with a structured interview guide, an employed moderator and assistant moderator. ${ }^{13,14}$ The composition of each group is shown in Table 1 . However, it should be noted that the groups did not appear consistently representative of their social occupational classification (SOC), especially the $\mathrm{AB}$ male group, in that some of the men tended to exaggerate their social status and there are weaknesses with the SOC rubric.

Content analysis was used to analyse the focus group data and provide an insight into the participants' beliefs, feelings and behavioural intentions towards unsolicited direct mail and telesales. Krippendorf defines content analysis as 'a research technique for making replaceable and valid inferences from the data in their context'. ${ }^{15}$ The major advantage of this method is that statements made by participants can be used in the discussion of the findings, rather than analysing each answer in relation to each question.

\section{Self-administered attitudinal survey}

A quantitative, self-administered survey of consumers living in Portsmouth, Hampshire was conducted. The specific objectives of the survey were to:

- determine the salience of consumer attitudes towards behaviour, subjective norm and perceived control in relation to unsolicited direct mail and telesales

— identify discrete segments by salient attitudes towards unsolicited direct mail and telesales

Two hundred and sixty-five respondents were selected based upon a quota.

Thirty-one of the completed questionnaires were rejected for reasons such as incompleteness. The remaining 234 valid returns were used in the analysis. The breakdown of the sample by gender, occupation, location and age is given in Table 2 .

Respondents were asked a variety of questions regarding their behaviour, intentions, attitudes, awareness, motivations, demographic and lifestyle characteristics. The survey was designed using direct and indirect measures of attitudes towards behaviour, specific media, subjective norm and perceived control. Attitude to behaviour is based upon the consequence to the action, known as positive or negative, identified as either instrumental (knowledge-based) or experiential (feelings-based). The questionnaire was designed to include 
Table 2: Composition of attitudinal survey

\begin{tabular}{|c|c|c|c|c|c|c|c|}
\hline \multicolumn{2}{|l|}{ Gender } & \multicolumn{2}{|l|}{ Occupation } & \multicolumn{2}{|c|}{ Location } & \multicolumn{2}{|c|}{ Age (years) } \\
\hline Male & $\begin{array}{l}51.8 \% \\
(116)\end{array}$ & $A B$ & $\begin{array}{l}32.6 \% \\
(71)\end{array}$ & Urban & $\begin{array}{l}78.5 \% \\
(175)\end{array}$ & $18-30$ & $\begin{array}{l}28.3 \% \\
(64)\end{array}$ \\
\hline \multirow[t]{2}{*}{ Female } & $\begin{array}{l}48.2 \% \\
(108)\end{array}$ & $\mathrm{C} 1$ and below & $\begin{array}{l}67.4 \% \\
(147)\end{array}$ & Rural & $\begin{array}{l}21.5 \% \\
(48)\end{array}$ & & $\begin{array}{l}39.8 \% \\
(90)\end{array}$ \\
\hline & & & & & & $45+$ & $\begin{array}{l}31.9 \% \\
(72)\end{array}$ \\
\hline Total & 234 & & 234 & & 234 & & 234 \\
\hline
\end{tabular}

measures of previous behaviour, direct and indirect measures of attitude towards the behaviour, measures of effect (positive or negative feelings towards behaviour), indirect measures of attitude towards the use of unsolicited direct mail and telesales, direct and indirect measures of subjective norm, direct and indirect measures of perceived control, direct and indirect measures of intention to use unsolicited direct mail, and direct and indirect measures of latency evaluation.

\section{FINDINGS}

\section{Findings from the focus groups}

Analysis and interpretation of the attitudes revealed by the participants indicated that their views were very mixed and were indeed part of a very complex attitudinal modelling system, displaying unrelated tangents and contradictory values and beliefs. Participants' beliefs were affected by many determining variables, such as past experience, expected outcome, referent beliefs, perceived control, sensitivity of the data and latency of contact.

In this study the themes identified as important by the participants were similar, or exactly the same, regardless of age, SOC, gender or location. Using content analysis, the themes generated from the data were subdivided into cognitive, affective and conative attitude components. ${ }^{16-18}$
A majority of the participants, particularly those that were highly targeted, held negative attitudes towards unsolicited direct mail and telesales, regardless of the product or service offered. Participants' attitudes towards telesales were considerably more negative than their attitudes towards direct mail.

Participants' concerns were mainly about information privacy, physical privacy, control, relevance, accuracy, intrusion, convenience, inappropriateness, wasting time and the environment.

When participants' attitudes were negative towards the media, they tended to also be negative towards the vendor, but not the agency or the information collector. Participants thought the offending organisation to be immoral, uncaring, insincere, ignorant, poorly managed, disrespectful, time wasters, with no sense of moral consideration or respect. This indicated that organisations could not hide behind the poor image of direct marketing, as the organisations were directly linked to the type of media they used.

This study identified that the issues of control and trust were significant driving forces in the shaping of consumers' negative attitudes. The intensity or salience of the individual's concern about control varied, depending on the perceived sensitivity of the personal data. A distinction was made between personal, financial and medical information and participants said that 
they were sensitive to the collection and use of different types of data.

The issue of control was expressed in a variety of ways, but mainly in the context of dissemination of consumer data, rather than the pursuit of it. The main concern expressed by participants was the issue of the data being swapped or sold, although none of the participants had complained officially or were aware of any of the regulatory bodies.

The unique selling proposition and benefit sought by the consumer was very much about gaining control. Control is fundamentally tangible whether it is perceived or actual. Therefore, it was concluded that policies which deal with issues relating to perceived and actual control are probably more useful than privacy policies. Consumer control worked within three layers: individual, organisational and governmental control - not necessarily in that order, as the prevalence would depend on the individual's need for control.

Lack of perceived or actual control led the author to considerations of 'trust'. Various workers have discussed the issue of trust, ${ }^{19-25}$ yet further research is needed to explore the underlying dimensions of trust in relation to specific media types. This study identified that the more trustworthy an organisation is seen to be, the more likely that consumers will have positive attitudes towards the ideas that they put forward and, arguably, trust can be increased through offering consumers increased control. This concept may be especially relevant when consumers are negatively disposed towards these ideas in the first place. Every interaction between parties will have an impact on the development of a relationship in which they are involved. Thus, both the acquisition of information by organisations, and their willingness to accept communication from consumers, will have an important influence on their ability to develop and enhance relationships with customers and their propensity to share information. Consumers are likely to be less anxious about potential abuses or negative consequences resulting from information supply if they trust the organisation. ${ }^{26}$

Thomas $^{27}$ continues this point by stating that, "the marketing communicator's task is clearly one of understanding every aspect of the organisation's output, value and goal system of orchestrating its trustworthiness'. Arguably, this can be achieved through an organisation giving full disclosure of how they intend to use the data collected, acknowledging mistakes when they are discovered and treating highly sensitive information in a strictly confidential manner. Participants could be categorised by their positive or negative attitudes, and by their passive or active responses, into four groups defined as 'active enjoyer', 'passive conformist', 'hard core resister' or an 'indifferent switcher' (see Table 3).

\section{Active enjoyers}

Active enjoyers actively enjoyed getting direct mail. They ticked the boxes to receive more mail and telephoned companies for more information. It was important for them to receive information through the post and they had made various purchases via this medium. They felt that they were able to purchase unique or specialist items and made reference to other benefits, such as convenience. They felt like they had a relationship with the organisation and that there was a high level of communication. Active enjoyers tended to be unaware of the data process, their need for privacy was limited, their usage rates were high and the nature of the contact tended to be solicited. Their personal circumstances, such as finances 
Table 3: Trust/distrust and control

\begin{tabular}{lll}
\hline & Positive attitude & Negative attitude \\
\hline $\begin{array}{l}\text { Active respondent } \\
\text { Passive respondent }\end{array}$ & Active enjoyers & Hard core resisters \\
\hline
\end{tabular}

and time availability, tended to fall at one or other end of the spectrum (eg, either on a low or high income, or with more free time than most people). Consumers felt that the organisation would protect their details, if only for financial gain, and that they were in control of the process.

\section{Passive conformists}

Passive conformists tended not to distinguish between advertising, personal selling or direct marketing. They perceived most types of marketing communication as necessary and part of everyday life. Purchases were limited, although constant. Passive conformists tended to have either a very busy social life and worked long hours, meaning that direct mail was irrelevant to them so they hardly ever read it, or they were unemployed so had plenty of time. Sometimes the letter was opened and other times it was put straight in the bin, depending on the attractiveness of the envelope or offer. Passive conformists did experience feelings of intrusion, yet they never did anything about it. They made statements that indicated that they had more important things to worry about and after all it was only a letter coming through the letterbox.

\section{Hard core resisters}

The hard core resisters were very emotional and expressive and tended to influence other people's feelings. They said that they hated direct mail and would never use it under any circumstances, even if it meant that they would get the right product or service at a cheaper price, or they could get products normally unavailable through any other distribution method. Hard core resisters actively telephoned and wrote protest letters demanding some explanation or compensation from the offending organisation which had used their personal details without consent. They distinguished very clearly between solicited and unsolicited contacts. For example, they were happy to receive marketing information about other products from their existing bank. It was definitely unsolicited mail that caused the problems. They would tell others about the organisation and its immoral behaviour and expect them to feel the same; they wanted supportive reactions reflecting their own personal concerns about the media, organisation and society in general. They tended to be on a high income and well educated. Their awareness of data processing methods was extensive, possibly because they worked for organisations that used unsolicited direct mail. Their need for privacy was paramount to them and their usage rates were zero. They felt that their trust had been abused and that they were not in control.

\section{Indifferent switcher}

The indifferent switcher was someone who changed his or her mind. It was as if they realised and accepted the benefits of direct mail, but felt some confusion over the negative issues relating to direct mail, as if it was not quite right. They 
demonstrated much more awareness than the passive conformists and were more expressive. If they used direct mail it would be for specialist products and/or on special occasions, such as Christmas. However, indifferent switchers felt no loyalty to the organisation and felt that a relationship was unnecessary. Indifferent switchers professed confusion and concerns, but were quick to use direct mail when it suited them. They appeared to have some awareness of the data process and were very aware of data collection methods. Their need for privacy was relatively high, yet the intrusion of direct mail was described as minimal in comparison with other forms of contact, such as telesales. They responded by putting the mail in the bin and felt in control. The nature of the contact was both solicited and unsolicited. Indifferent switchers included blanket mail drops and leafleting under the heading of 'direct mail'.

In summary, the salient beliefs held by the indifferent switchers and the passive conformists were about relevance, timeliness, appropriateness, the environment, intrusion, physical privacy, information privacy and accuracy. In comparison, the salient beliefs held by the active resisters and positive enjoyers were more related to trust and control. The implication of this is that direct marketers need to adopt different strategies for each segment, acknowledging the individual segments and making the consumer feel more at ease with the contact. For example, the active resister needs to have an immediate response from the organisation, deflecting the negative feelings about direct mail away from the organisation. Actively responding to the consumer, the organisation should apologise when in the wrong and give a full explanation of what has been done to protect the consumer in the future, ensuring that the consumer's personal details will not be used for further contact and guaranteeing the consumer confidentiality. The organisation should take responsibility for their actions and avoid defending their behaviour. In some instances the vendor should trace the personal data structure to the initial collector and provider. A monthly update would be sufficient and would probably work much faster than the mailing preference service.

The offending organisation could improve matters by tracing where the data have been sold on to and encourage contractual obligations between the two parties to delete the name purchased or sold/swapped. Organisations should respond and react to the consumer in a polite and sincere fashion, regaining wherever possible their trust and future custom. Whereas the active enjoyers, would need an active and ongoing response from the organisation, active resisters would need the constant reassurance of being in control, encouraging a feeling of trust. Strategies used by relationship marketers would need to be adopted and the consumer would need to feel safe and secure within the relationship.

These results clearly highlight that there is a clear distinction between control, privacy and intrusion, shifting the area of concern away from consumer privacy and towards consumer control and trust. The results from the focus groups determined and prioritised the themes for the attitudinal survey, linking the two separate research stages together.

\section{Findings from the attitudinal survey}

Although attitudes towards advertising appeared to cause some distress, they did not invade consumer privacy to any significant level, whereas personal selling did. When compared with unsolicited 
direct mail and telesales, respondents were definitely less concerned with advertising and personal selling. The responses clearly represented an overwhelming view that unsolicited direct mail is uninteresting, uninformative, damages the environment, arrives at the wrong time, wastes time and is mostly irrelevant to respondents' needs. Unsolicited telesales were also found uninteresting, uninformative, inappropriate and unrelated to respondents' needs.

Multivariate analysis identified that these classifications could be segmented further, and that age was identified as a key discriminating factor. Factor analysis identified that there was a fundamental difference between the factor loading for telesales and direct mail. The younger age groups were more discriminatory towards direct mail and telesales, whereas the older age bands tended to be media general.

By placing each attitudinal group in order of importance (see Table 4), it was possible to compare and contrast subtle shifts between the older age groups and the younger age groups. This revealed that attitudes did indeed fall into specific segments that could be categorised as follows:

- privacy seekers: concern themselves with direct mail itself and are concerned that organisations have their personal details

- hostile reactors: hold negative perceptions about personal selling and telesales

- physical invaders: concerned about physical invasion of personal selling and telesales

- advertising accepters: not concerned about physical invasion in relation to advertising in general

- advertising sufferers: said that inappropriate advertising caused them distress
- policy rejecters: held negative attitudes and rejected the organisation's policy suggestions about consumer privacy

- government regulators: felt that the government should regulate and control unsolicited direct mail and telesales

- individual controllers: felt that the individual should regulate and control unsolicited direct mail and telesales

- organisational distrusters: felt that the organisation could not be trusted to regulate and control unsolicited direct mail and telesales.

The analysis resulted in a useful list of segments which may have implications for the design and execution of organisations' marketing communications plans. The list provides an insight into differing attitudes within age bands and could be used by organisations to segment, target and position the specific media type, organisation, product or service more effectively in the consumer's mind.

The outcome of the analysis suggests that the younger age bands were more discriminating than the older age group. The younger age bands tended to form their attitudes on direct mail itself, whereas the older age group tended to take a broadbrush view, based upon their general experiences of personal selling and advertising. For direct marketers, this is probably a positive finding from an educational point of view, because the young, emerging consumer appears to be more discerning about different media types. As direct mail and telesales develop, attitudes are likely to become more positive if strategies within the industry become more sophisticated. On the other hand, the findings indicate a hostile attitude towards telesales throughout all the age bands. 
Table 4: Hierarchical factor solution

\begin{tabular}{|c|c|c|}
\hline $\begin{array}{l}\text { Age } \\
\text { (years) }\end{array}$ & Direct mail & Telesales \\
\hline $18-30$ & $\begin{array}{l}\text { 1. Direct mail privacy seekers }(26.1 \%) \\
\text { 2. Hostile reactor to personal selling }(21.8 \%) \\
\text { 3. Advertising accepters and advertising } \\
\text { sufferers }(17.0 \%)\end{array}$ & $\begin{array}{l}\text { 1. Hostile reactor/physical invaders }(37.9 \%) \\
\text { 2. Advertising accepters }(26.5 \%)\end{array}$ \\
\hline $31-44$ & $\begin{array}{l}\text { 1. Hostile reactor/advertising sufferer }(28.0 \%) \\
\text { 2. Direct mail privacy seekers }(25.1 \%) \\
\text { 3. Advertising accepters }(15.9 \%)\end{array}$ & $\begin{array}{l}\text { 1. Hostile reactor }(32.9 \%) \\
\text { 2. Hostile reactor/advertising sufferer and } \\
\text { physical invader }(31.3 \%)\end{array}$ \\
\hline $45+$ & $\begin{array}{l}\text { 1. Hostile reactor/advertising sufferer }(35.6 \%) \\
\text { 2. Direct mail privacy seekers }(32.8 \%)\end{array}$ & $\begin{array}{l}\text { 1. Hostile reactor/advertising sufferer and } \\
\text { physical invader ( } 37.3 \%) \\
\text { 2. Hostile reactor/organisational distrusters } \\
(34.2 \%)\end{array}$ \\
\hline
\end{tabular}

\section{DISCUSSION AND CONCLUSIONS}

This study supports the author's initial hypothesis that consumers could be segmented into discrete, identifiable groups based upon their thresholds towards privacy and physical privacy. It was concluded that organisations need to manage consumers' negative attitudes towards direct marketing on different levels, and they need to go somewhat further than at present in their attitudinal segmentation. They also need to be more self-regulatory in order to avoid strengthening negative attitudes.

Segmenting consumers on attitudes alone is not a practical proposition yet, but the employment of a multivariate segmentation approach is recommended by the author. Organisations need to do more than merely reinforce positive attitudes through re-education programmes. They need to develop strategic marketing plans which follow a long-term, ethical business perspective.

This study highlights that there is a clear distinction between control, privacy and intrusion. This study shifts the area of concern away from consumer privacy and towards consumer control and trust. The concerns held by consumers are deep rooted and reflect their attitudes towards the media, the communications strategy used, the organisation, and government and society as a whole.

Attitudinal communications segmentation will clearly help an organisation to plan its communications strategies. The survey findings demonstrated that the desire for control by consumers was a function of the lack of trust, highlighting that there is a dynamic relationship between trust and control, rather than a linear relationship ${ }^{28}$ or antecedent and consequential relationship. This has implications for model building in the future.

The survey results suggest there may be an educational role for organisations to encourage older age cohorts to distinguish between direct mail and advertising and personal selling. The inability of the older age groups to differentiate between media types highlights the lack of effectiveness in organisational messages.

The initial problem with gaining control and/or building a relationship is that there is an underlying assumption that consumers want to be involved with the organisation, above and beyond the action of purchase. In some cases this is true, but in other purchase situations it is not. Some participants in the focus groups refuted the need for a relationship, or to be actively in control, as they said this took time and energy. 
The level of involvement taking place between the customer and the organisation will depend on many issues and the context of 'control' and 'customer relationships' cannot be assumed to be always a natural or profitable way forward. In brief, the onus is on the organisation and not the consumer to create an environment where the consumer feels in control and can trust the organisation. This is not to suggest that consumers necessarily want to adopt a passive role within the interaction, yet they do expect that issues relating to control will be taken care of by the organisation and that organisations will behave in a way that will continue to instil consumer trust.

Understanding consumers' attitudes towards specific media types is a central theoretical issue. It is vital to understand the segments which can be derived from the attitudes. Attitudinal segmentation is by no means a new idea and has been used successfully in branding and by the financial sector. Trust is seen as an essential ingredient and the power of trust used in transforming channel relationships should be observed as an example of empirical models of channel relationships. The challenge in segmenting consumers based upon their attitudes towards specific media types is understanding the trade-off between consumers' negative attitudes about individual privacy or control, compared to the cost of developing new acquisition strategies. Indeed, Gronmo and Olander ${ }^{29}$ stated that consumers will increasingly find a voice in expressing their dissatisfaction with the failure of companies to recognise their responsibilities in the use of personal data. One study ${ }^{30}$ identified that consumers have different thresholds for privacy depending on who is collecting the information, under what circumstances and for what purpose.
They cited examples where organisations had to withdraw their plans to 'sell on' subscriber information after the companies received a stream of complaints.

Participants in the focus groups talked mainly about the control of data, rather than privacy or intrusion; in most situations they were talking about trust, rather than complete control. This was felt to be an important finding. Based upon the evidence of this study, the author proposes that control and trust are central in the development of a marketing communications plan. Understanding the levels of control and trust felt by the consumer will help companies to identify appropriate strategies for alleviating customers' concerns about the use of information technology for collecting, analysing and exploiting customer data.

Consumer control seems to depend mainly on consumers' privacy thresholds which are affected by both internal and external factors. Internal factors include the level of involvement with the organisation; external factors include the type of data being collected, how they are collected, the situation in which they are collected, the reputation of the organisation collecting the data, the purpose for which they are being collected and the likelihood of the data being sold or swapped. The importance of understanding consumer trust as a complex and multifaceted construct and its role in facilitating accessibility, propensity to respond and targetability should be recognised as the competitive core of direct marketing activities.

\section{References}

1 Campbell, A. J. (1997) 'Relationship marketing in consumer markets', Journal of Direct Marketing, Vol. 9, No. 3, pp. 44-57.

2 Milne, G. R. and Gordon, M. E. (1994) 'A segmentation study of consumers' attitudes toward 
direct mail', Journal of Direct Marketing, Vol. 8, No. 2, pp. $45-52$.

3 Nowak, G. and Phelps, J. (1995) 'Direct marketing and the use of individual-level consumer information: Determining how and when "privacy" matters', Journal of Direct Marketing, Vol. 9, No. 3, pp. 46-60.

4 Goodwin, C. (1991) 'Privacy: Recognition of a consumer right', Journal of Public Policy and Marketing, Vol. 10, No. 1, pp. 149-166.

5 Mitchell, S. and Christy, R. (1999) 'Privacy matters', Journal of Targeting, Measurement and Analysis for Marketing, Vol. 8, No. 1, pp. 8-20.

6 Calder, B. J. (1977) 'Focus groups and the nature of qualitative marketing research', Journal of Marketing Research, Vol. 17, No. 10, pp. 353-364.

7 Ibid.

8 Basch, C. E. (1987) 'Focus group interview: An under-utilised research technique for improving theory and practice in health education', Health Education Quarterly, Vol. 14, No. 4, pp. 411-448.

9 Malhotra, N. K. (1996) Marketing Research: An Applied Orientation, Prentice Hall, New Jersey.

10 McQuarrie, E. F. (1996) The Market Research Toolbox: A Concise Guide for Beginners, Sage, London.

11 Malhotra (1996) op. cit.

12 Morgan, D. L. (1997) Focus Groups as Qualitative Research, Sage, Los Angeles, CA, USA.

13 Ibid.

14 McQuarrie (1996) op. cit.

15 Krippendorf, K. (1980) 'Content analysis in consumer research', Journal of Consumer Research, Vol. 4, June, p. 21.

16 Engel, J. F., Blackwell, R. D. and Miniard, P. W. (1995) Consumer Behavior, Dryden Press, Orlando, FL, USA.

17 Schiffman, L. G. and Kanuk, L. L. (1994) Consumer Behavior, Prentice Hall, Englewood Cliffs, NJ, USA.

18 Loudon, D. and Bitta, A. (1993) Consumer Behaviour; Concepts and Applications, McGraw-Hill,
Louisiana, USA.

19 O’Malley, L. and Tynan, C. (1997) A Reappraisal of the Relationship Marketing Constructs of Commitment and Trust, American Marketing Association, Dublin, Ireland.

20 Fletcher, K. P. and Peters, L. D. (1997) 'Trust and direct marketing environments: A consumer perspective', Journal of Marketing Management, Vol. 13 , pp. 523-539.

21 Ganesan, S. (1994) 'Determinants of long-term orientation in buyer-seller relationships', Journal of Marketing, Vol. 58, April, pp. 1-19.

22 Morgan, R. M. and Hunt, S. D. (1994) 'The commitment-trust theory of relationship marketing', Journal of Marketing, Vol. 58, July, pp. 20-38.

23 Smith-Ring, P. and Van de Ven, A. (1992) 'Structuring cooperative relationships between organizations', Strategic Management Journal, Vol. 13, April, pp. 483-498.

24 Butler, J. K. Jr. (1991) 'Toward understanding and measuring conditions of trust: Evolution of a conditions of trust inventory', Journal of Management, Vol. 17, No. 3, pp. 643-663.

25 Zucker, I. (1986) 'Production of trust: Institutional sources of economic structure 1984-1920', Research in Organisational Behaviour, Vol. 8, pp. 53-111.

26 Gandy, O. H. (1993) The Panoptic Sort: A Political Economy of Personal Information, Westview Press, Boulder, CO, USA.

27 Thomas, H. (1992) 'Is the map to be redrawn?', Marketing, Vol. 20, February, p. 19.

28 Fletcher and Peters (1997) op. cit.

29 Gronmo, S. and Olander, F. (1991) 'Consumer power: Enabling and limiting factors', Journal of Consumer Policy, Vol. 14, pp. 141-169.

30 Long, G., Hogg, M. K., Hartley, M. and Hartley, S. J. (1999) 'Relationship marketing and privacy: Exploring the thresholds', Journal of Marketing Practice: Applied Marketing Science, Vol. 5, No. 1, pp. 4-20. 